\title{
Prediction of survival after eribulin chemotherapy for breast cancer by absolute lymphocyte counts and progression types
}

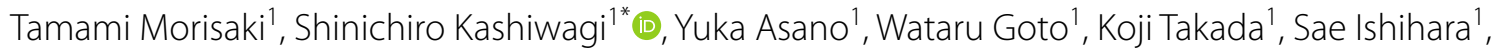
Masatsune Shibutani², Hiroaki Tanaka², Kosei Hirakawa ${ }^{1,2}$ and Masaichi Ohira ${ }^{1,2}$

\begin{abstract}
Background: In the Response Evaluation Criteria for Solid Tumors (RECIST) diagnostic criteria, the concepts of progression by preexisting disease (PPL) and progression by new metastases (PNM) have been proposed to distinguish between the progression types of cancer refractory to treatment. According to the tumor biology of cancer progression forms, the "PPL" form indicates invasion, and the "PNM" form indicates metastasis. On the other hand, recent studies have focused on the clinical importance of inflammatory markers as indicators of the systemic tumor immune response. In particular, absolute lymphocyte count (ALC) is an indicator of the host's immune response. Thus, we developed a new measure that combined progression form with ALC. In this study, we clinically validated the combined assessment of progression form and ALC in eribulin chemotherapy.

Methods: From August 2011 to April 2019, a total of 486 patients with locally advanced or metastatic breast cancer (MBC) underwent treatment. In this study, only 88 patients who underwent chemotherapy using eribulin were included. The antitumor effect was evaluated based on the RECIST criteria, version 1.1. To measure ALC, peripheral blood samples collected before eribulin treatment were used. The cut-off value for ALC in this study was 1500/ $\mu$, based on previous studies.
\end{abstract}

Results: The PPL group (71 patients, $80.7 \%)$ had significantly longer progression-free survival (PFS) $(p=0.022$, logrank) and overall survival (OS) ( $p<0.001$, log-rank) than the PNM group (17 patients, 19.3\%). In the 51 patients with ALC $<1500 / \mu \mathrm{l}$, the PPL group had a significantly better prognosis than the PNM group (PFS: $p=0.035$, OS: $p<0.001$, log-rank, respectively). On the other hand, in the 37 patients with ALC $\geq 1500 / \mu l$, the PPL group had a better OS compared with the PNM group ( $p=0.055$, log-rank), but there was no significant difference in PFS between the two groups ( $p=0.541$, log-rank). Furthermore, multivariate analysis that validated the effect of OS showed that high ORR and "high-ALC and PPL" were factors for a good prognosis ( $p<0.001, H R=0.321 ; p=0.036, H R=0.290$ ).

Conclusions: The progression form of PNM had a worse prognosis than PPL in patients treated with eribulin. In breast cancer patients with eribulin chemotherapy, good systemic immune status, such as ALC $\geq 1500 / \mu \mathrm{l}$, was associated with less progression, particularly metastasis, and better prognosis. Furthermore, the biomarker "high-ALC (ALC $\geq$ $1500 / \mu l)$ and PPL" was particularly useful as a prognostic marker following eribulin chemotherapy.

\footnotetext{
*Correspondence: spqv9ke9@view.ocn.ne.jp

${ }^{1}$ Department of Breast and Endocrine Surgery, Osaka City University

Graduate School of Medicine, 1-4-3 Asahi-machi, Abeno-ku,

Osaka 545-8585, Japan

Full list of author information is available at the end of the article
}

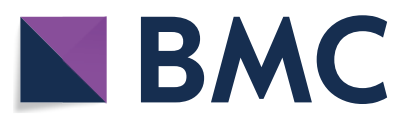

(c) The Author(s) 2021. Open Access This article is licensed under a Creative Commons Attribution 4.0 International License, which permits use, sharing, adaptation, distribution and reproduction in any medium or format, as long as you give appropriate credit to the original author(s) and the source, provide a link to the Creative Commons licence, and indicate if changes were made. The images or other third party material in this article are included in the article's Creative Commons licence, unless indicated otherwise in a credit line to the material. If material is not included in the article's Creative Commons licence and your intended use is not permitted by statutory regulation or exceeds the permitted use, you will need to obtain permission directly from the copyright holder. To view a copy of this licence, visit http://creativecommons.org/licenses/by/4.0/. The Creative Commons Public Domain Dedication waiver (http://creativeco mmons.org/publicdomain/zero/1.0/) applies to the data made available in this article, unless otherwise stated in a credit line to the data. 
Keywords: Eribulin, Breast cancer, RECIST, Prognostic marker, Absolute lymphocyte counts

\section{Background}

The Response Evaluation Criteria for Solid Tumors (RECIST) plays an important role in determining the response to chemotherapy for solid tumors as well as the treatment strategy [1]. In the RECIST diagnostic criteria, the concepts of progression by preexisting disease (PPL) and progression by new metastases (PNM) have been proposed to distinguish between the progression types of cancer refractory to treatment [2, 3]. Since both PPL and PNM are evaluated as "progression disease (PD)" by the RECIST diagnostic criteria, the difference in the form of progression has not influenced the choice of treatment. However, according to the tumor biology of cancer progression forms, the "PPL" form indicates invasion, and the "PNM" form indicates metastasis. Our previous study showed that patients with PPL who had good tumor immune microenvironment conditions had a good prognosis after eribulin chemotherapy [4].

On the other hand, recent studies have focused on the clinical importance of inflammatory markers as indicators of the systemic tumor immune response [5, 6]. The in vivo inflammatory response contributes to cancer progression. The peripheral blood neutrophil-lymphocyte ratio (NLR), lymphocyte-monocyte ratio (LMR), and platelet-lymphocyte ratio (PLR) of cancer patients have been proposed as indicators of the systemic inflammatory response [7-11]. In addition, several studies have reported that these factors predicted the prognosis of various carcinomas [12-15]. These inflammatory markers reflect a systemic tumor immune response. In particular, the absolute lymphocyte count (ALC) is an indicator of the host's immune response.

In a phase III clinical trial on patients with locally advanced or metastatic breast cancer (MBC), eribulin significantly prolonged the overall survival (OS) (study 305, EMBRACE) [16]. Furthermore, the survival curve showed a characteristic pattern called the delayed separation curve in immunotherapy. Thus, this pattern may reflect the effects of eribulin on tumor immune response. A retrospective analysis of this trial showed that ALC was a useful marker in predicting the therapeutic effect of eribulin chemotherapy [17]. Additionally, real-world data on MBC patients treated with eribulin have reported on NLR, ALC prognosis, and predictors of therapeutic efficacy $[18,19]$.

We hypothesized that the combination of both the "form of PD" and the "host's immune systemic marker, ALC" was a more sensitive indicator than ALC alone. Thus, we developed a new measure that combined progression form with ALC. In this study, we clinically validated the combined assessment of progression form and ALC in eribulin chemotherapy.

\section{Methods \\ Patient background}

From August 2011 to April 2019, a total of 486 patients with MBC underwent treatment at the Osaka City University Hospital. In this study, only 88 patients who underwent chemotherapy using eribulin were included, and 380 patients who were administered with other drug therapies, such as endocrine therapy or other chemotherapy regimens, and 18 patients who dropped out due to surgery or adverse events were excluded (Fig. 1). This dataset of eribulin chemotherapy was partially used in previous studies [20-22]. The median follow-up time for eribulin chemotherapy patients was 478 days (range: 50-2267 days). The chemotherapy regimen consisted of one course of treatment for 21 days (3 weeks), and eribulin mesylate $\left(1.4 \mathrm{mg} / \mathrm{m}^{2}\right)$ was intravenously administered on days 1 and $8[16,23]$. This protocol was followed repeatedly until PD was evaluated or therapy was discontinued due to severe adverse events. Chemotherapy was administered in all cases on an outpatient basis.

Based on the efficacy of this regimen, the objective response rate (ORR), OS, and progression-free survival (PFS) were determined. ORR was evaluated by adding complete response (CR) and partial response (PR). OS was defined as the time from the date of treatment initiation to death (daily). PFS was defined as the time from the date of treatment initiation to the date of death or PD confirmation, whichever was earlier (daily). The antitumor effect was evaluated based on the RECIST criteria, version 1.1 [1].

\section{Classification based on progression types}

According to the RECIST guidelines, PPL is described as an increase by at least $20 \%$ in the sum of the diameter of the lesion evaluated or an absolute increase of $5 \mathrm{~mm}$ or more in the sum of the diameter from the lowest sum of the diameter to date [2, 3]. PNM was defined as a new lesion, indicative of disease progression, identified during a follow-up session. If PPL and PNM were observed simultaneously during the evaluation, it was considered a PNM.

\section{Blood sample analysis}

To measure ALC, peripheral blood samples collected before eribulin treatment were used. The percentage of 


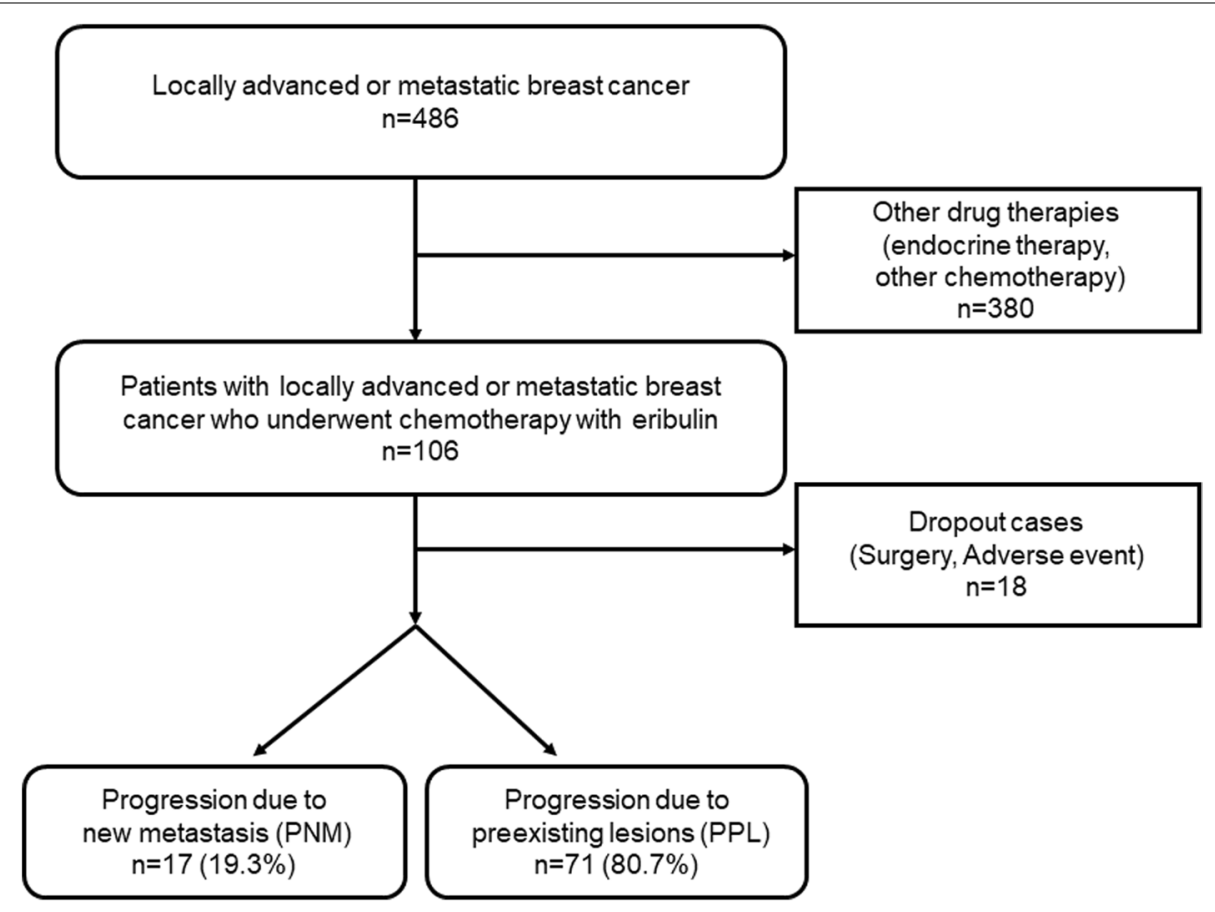

Fig. 1 Consort diagram. From August 2011 to April 2019, a total of 486 patients with MBC underwent treatment at the Osaka City University Hospital. In this study, only 88 patients who underwent chemotherapy using eribulin were included, and 380 patients who were administered with other drug therapies, such as endocrine therapy or other chemotherapy regimens, and 18 patients who dropped out due to surgery or adverse events were excluded

white blood cells was measured using a Coulter LH750 blood analyzer (Beckman Coulter, Brea, CA, USA). The cut-off value for ALC in this study was $1500 / \mu \mathrm{l}$, based on previous studies $[17,18,24]$. ALC values $\geq 1500 / \mu \mathrm{l}$ were considered high, while values below $1500 / \mu \mathrm{l}$ were low.

\section{Statistical analysis}

We used SPSS ${ }^{\circledR}$ Statistics version 25 statistical software (IBM, Armonk, NY, USA) for the statistical analysis. To analyze whether clinical parameters were associated with ALC, the chi-squared test or Fisher's exact test was used as appropriate. The association with survival was analyzed using Kaplan-Meier plots and the log-rank test. Cox proportional hazards models were used to calculate univariate and multivariate hazard ratios (HRs) for the study parameters with $95 \%$ confidence intervals (CIs). The selection of variables in the multivariate analysis included a backward stepwise method. For all statistical tests, a $p$ value of less than 0.05 was considered statistically significant.

\section{Ethics statement}

This study complies with the provisions of the Declaration of Helsinki (64th WMA General Assembly, Fortaleza, Brazil, October 2013). This study consisted of a retrospective chart review. While receiving treatment, patients provided written informed consent for the use of patient data in later research studies. This research protocol was approved by the Ethics Committee of Osaka City University (\#926).

\section{Results}

Differences in progression types and prognostic analysis

Among the $106 \mathrm{MBC}$ patients who received chemotherapy with eribulin, 88 were included in the study, and 18 patients were excluded. Among them, 17 patients (19.3\%) were PNM, and 71 patients $(80.7 \%)$ were PPL. The PPL group had significantly longer PFS ( $p=0.022, \log$-rank) and OS ( $p<0.001, \log$-rank) than the PNM group (Fig. 2).

\section{Absolute lymphocyte counts and differences in progression types}

Among the 88 patients, $37(42.0 \%)$ were included in the high-ALC group, and 51 (58.0\%) were in the low-ALC group. Among the 17 patients in the PNM group, 5 were classified in the high-ALC group (29.4\%), and 12 were in the low-ALC group (70.6\%). Among the 71 patients in the PPL group, 32 (45.1\%) were classified in the highALC group, and 39 (54.9\%) were in the low-ALC group. When the groups were divided based on the difference in ALC, there was no significant difference between the clinicopathological parameter and ALC (Table 1). 


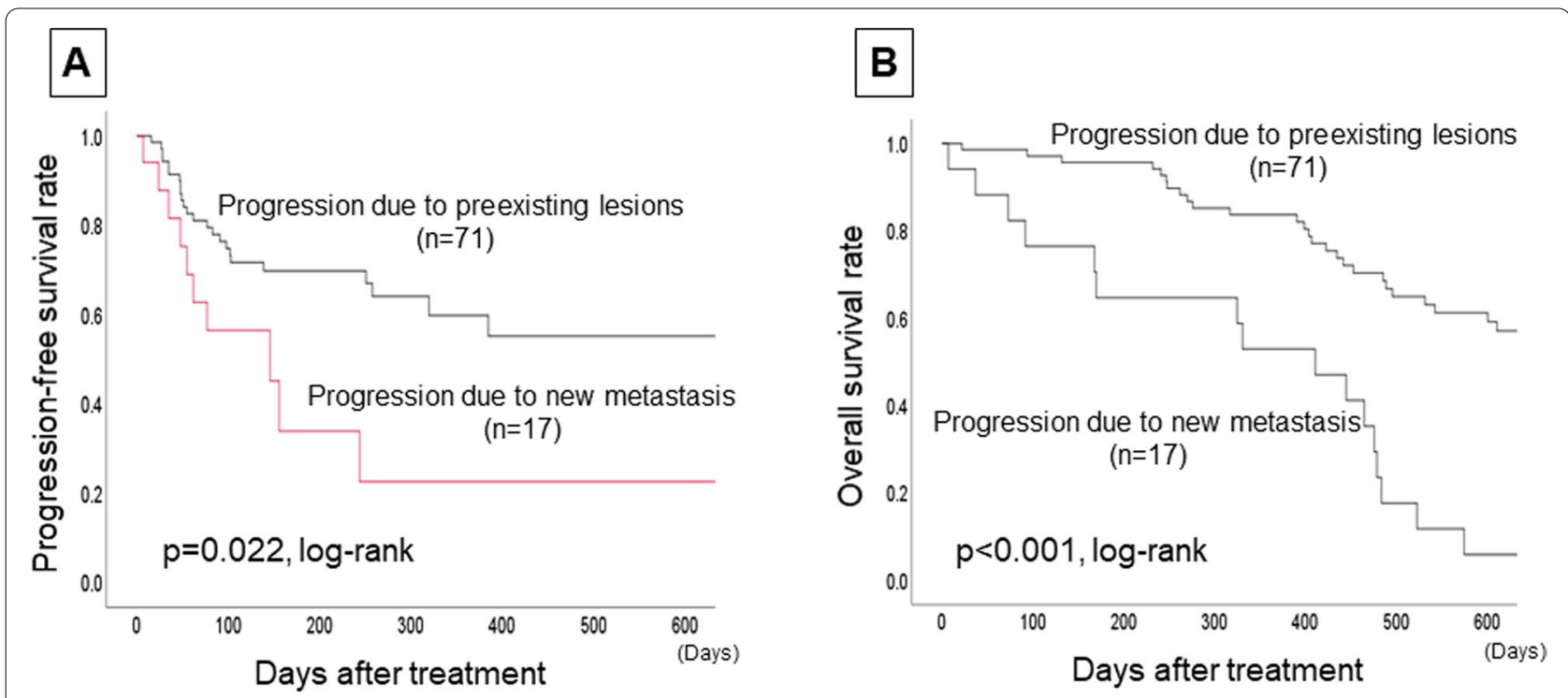

Fig. 2 Differences in progression types and prognostic analysis. The 71 patients of the PPL group had significantly longer PFS $(p=0.022$, log-rank) (A) and OS ( $p<0.001$, log-rank) (B) than the 17 patients of the PNM group

Table 1 Correlations between absolute lymphocyte counts and clinicopathological parameters in 88 patients with eribulin chemotherapy for locally advanced or metastatic breast cancer

\begin{tabular}{|c|c|c|c|c|c|c|c|c|c|}
\hline \multirow[t]{2}{*}{ Parameters } & \multicolumn{2}{|c|}{$\begin{array}{l}\text { All breast cancer } \\
(n=88)\end{array}$} & \multirow[b]{2}{*}{$p$ value } & \multicolumn{2}{|c|}{$\begin{array}{l}\text { Progression due to new } \\
\text { metastasis } \\
(n=17)\end{array}$} & \multirow[b]{2}{*}{$p$ value } & \multicolumn{2}{|c|}{$\begin{array}{l}\text { Progression due to } \\
\text { preexisting lesions } \\
(n=71)\end{array}$} & \multirow[b]{2}{*}{$p$ value } \\
\hline & High $(n=37)$ & Low $(n=51)$ & & High $(n=5)$ & Low $(n=12)$ & & $\operatorname{High}(n=32)$ & Low $(n=39)$ & \\
\hline \multicolumn{10}{|l|}{ Age at chemotherapy } \\
\hline$\leq 63$ & 24 (64.9\%) & $28(54.9 \%)$ & & $3(60.0 \%)$ & $6(50.0 \%)$ & & $21(65.6 \%)$ & $22(56.4)$ & \\
\hline$>63$ & $13(35.1 \%)$ & $23(45.1 \%)$ & 0.348 & $2(40.0 \%)$ & $6(50.0 \%)$ & 0.563 & $11(34.4 \%)$ & $17(43.6 \%)$ & 0.293 \\
\hline \multicolumn{10}{|l|}{ Degree of progress } \\
\hline Locally advanced & $11(29.7 \%)$ & $13(25.5 \%)$ & & $1(20.0 \%)$ & $5(41.7 \%)$ & & $10(31.3 \%)$ & $8(20.5 \%)$ & \\
\hline Visceral metastases & $26(70.3 \%)$ & $38(74.5 \%)$ & 0.659 & $4(80.0 \%)$ & $7(58.3 \%)$ & 0.395 & $22(68.7 \%)$ & $31(79.5 \%)$ & 0.301 \\
\hline \multicolumn{10}{|c|}{ HR (ER and/or PgR) status } \\
\hline Negative & $12(32.4 \%)$ & $21(41.2 \%)$ & & $1(20.0 \%)$ & $6(50.0 \%)$ & & $11(34.4 \%)$ & $15(38.5 \%)$ & \\
\hline Positive & $25(67.6 \%)$ & $30(58.8 \%)$ & 0.403 & $4(80.0 \%)$ & $6(50.0 \%)$ & 0.278 & $21(65.6 \%)$ & $24(61.5 \%)$ & 0.722 \\
\hline \multicolumn{10}{|l|}{ HER2 status } \\
\hline Negative & $33(89.2 \%)$ & $47(92.2 \%)$ & & $5(100.0 \%)$ & $12(100.0 \%)$ & & $28(87.5 \%)$ & $35(89.7 \%)$ & \\
\hline Positive & $4(10.8 \%)$ & $4(7.8 \%)$ & 0.633 & $0(0.0 \%)$ & $0(0.0 \%)$ & - & $4(12.5 \%)$ & $4(10.3 \%)$ & 0.527 \\
\hline \multicolumn{10}{|l|}{ Ki67 } \\
\hline Low & $21(56.8 \%)$ & $30(58.8 \%)$ & & $2(40.0 \%)$ & $4(33.3 \%)$ & & $19(59.4 \%)$ & $26(66.7 \%)$ & \\
\hline High & $16(43.2 \%)$ & $21(41.2 \%)$ & 0.846 & $3(60.0 \%)$ & $8(66.7 \%)$ & 0.605 & $13(40.6 \%)$ & $13(33.3 \%)$ & 0.526 \\
\hline \multicolumn{10}{|l|}{ Nuclear grade } \\
\hline 1,2 & $24(64.9 \%)$ & $38(74.5 \%)$ & & $3(60.0 \%)$ & $8(66.7 \%)$ & & $21(65.6 \%)$ & $30(76.9 \%)$ & \\
\hline 3 & $13(35.1 \%)$ & $13(25.5 \%)$ & 0.328 & $2(40.0 \%)$ & $4(33.3 \%)$ & 0.605 & $11(34.4 \%)$ & $9(23.1 \%)$ & 0.292 \\
\hline \multicolumn{10}{|l|}{ Objective response rate } \\
\hline ORR & $23(62.2 \%)$ & $18(35.3 \%)$ & & $3(60.0 \%)$ & $2(16.7 \%)$ & & $20(62.5 \%)$ & $16(41.0 \%)$ & \\
\hline Non-ORR & $14(37.8 \%)$ & 33 (64.7\%) & 0.013 & $2(40.0 \%)$ & $10(83.3 \%)$ & 0.117 & $12(37.5 \%)$ & $23(59.0 \%)$ & 0.072 \\
\hline
\end{tabular}

$H R$ hormone receptor, ER estrogen receptor, PgR progesterone receptor, HER2 human epidermal growth factor receptor, ORR objective response rate 


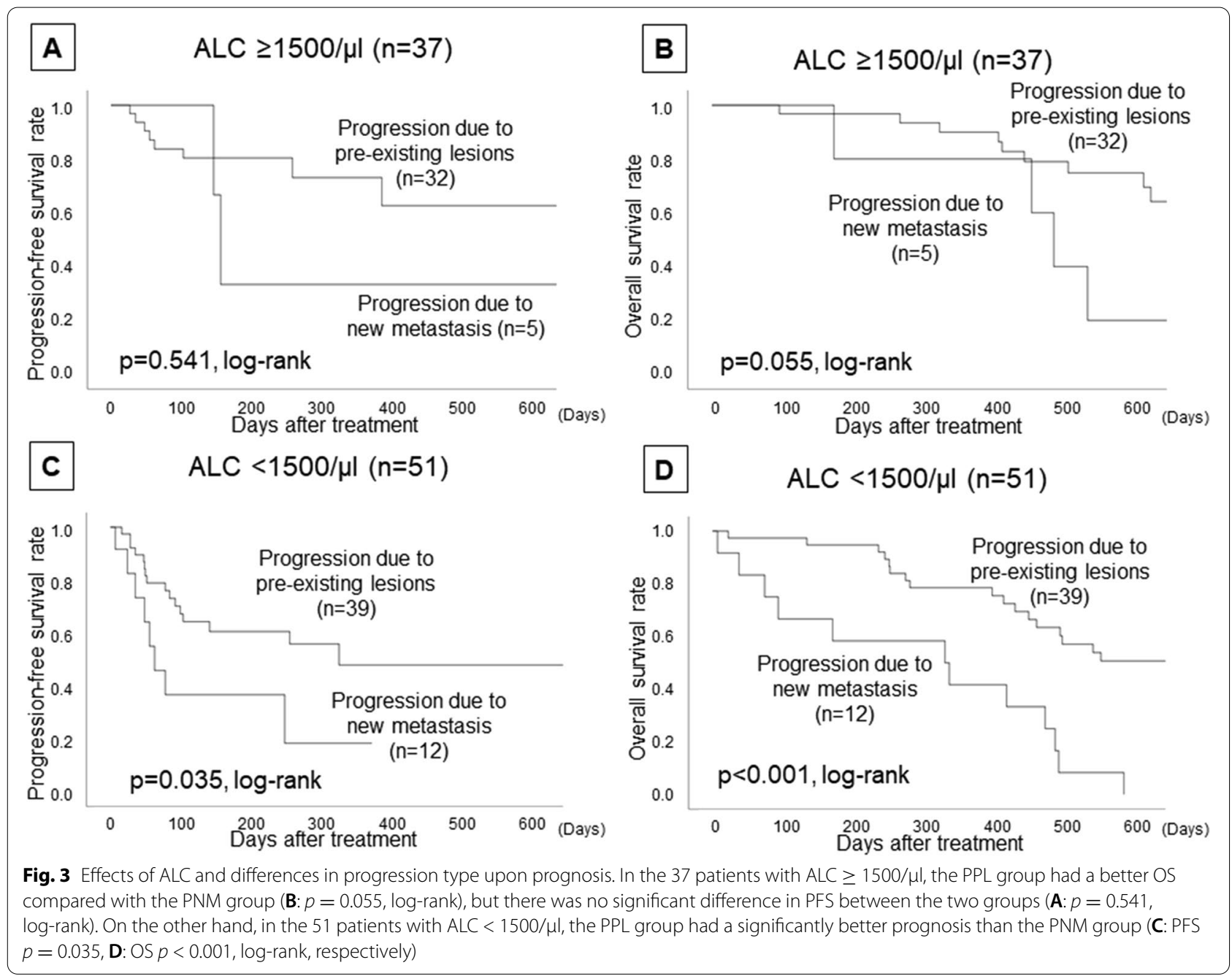

\section{Effects of ALC and differences in progression type upon prognosis}

In the 51 patients with $\mathrm{ALC}<1500 / \mu \mathrm{l}$, the PPL group had a significantly better prognosis than the PNM group (PFS: $p=0.035$, OS: $p<0.001$, log-rank, respectively) (Fig. 3). On the other hand, in the 37 patients with ALC $\geq 1500 / \mu \mathrm{l}$, the PPL group had a better OS compared with the PNM group ( $p=0.055$, log-rank), but there was no significant difference in PFS between the two groups ( $p=0.541, \log$-rank).

A univariate analysis that validated the effect of OS showed that high ORR, high-ALC, and "high-ALC and PPL" were factors for a good prognosis $(p<0.001, H R$ $=0.310,95 \%$ CI: 0.170-0.568) $(p=0.027, H R=0.505$, 95\% CI: 0.275-0.926) $(p=0.009, H R=0.407,95 \% \mathrm{CI}$ : 0.208-0.795) (Fig. 4). Receiver operating characteristic (ROC) analysis showed that the results for "high-ALC and PPL" (area under the curve (AUC): 0.666) were better than those for the ALC (AUC: 0.639), "low-ALC and PPL"
(AUC: 0.455), "high-ALC and PNM" (AUC: 0.473), and "low-ALC and PNM" (AUC: 0.406) (Fig. 5). Furthermore, multivariate analysis demonstrated that ORR was the strongest independent factor for a favorable prognosis $(p$ $<0.001, H R=0.321$, 95\% CI: 0.171-0.602). In addition, "high-ALC and PPL" was another independent factor for a favorable prognosis $(p=0.036, H R=0.290,95 \% \mathrm{CI}$ : 0.091-0.923) (Table 2).

\section{Discussion}

Eribulin chemotherapy for $\mathrm{MBC}$ patients has been shown to prolong OS in international phase III clinical trials (Study 305, EMBRACE) [16]. Prolonging OS in $\mathrm{MBC}$, which is biologically mild and has more treatment options, is difficult. Bevacizumab combination therapy has a high response rate and has been shown to improve PFS, but it did not significantly affect OS (E2100, AVADO, RIBBON-1) [25-28]. Meanwhile, eribulin chemotherapy benefitted MBC patients by improving the OS. However, 


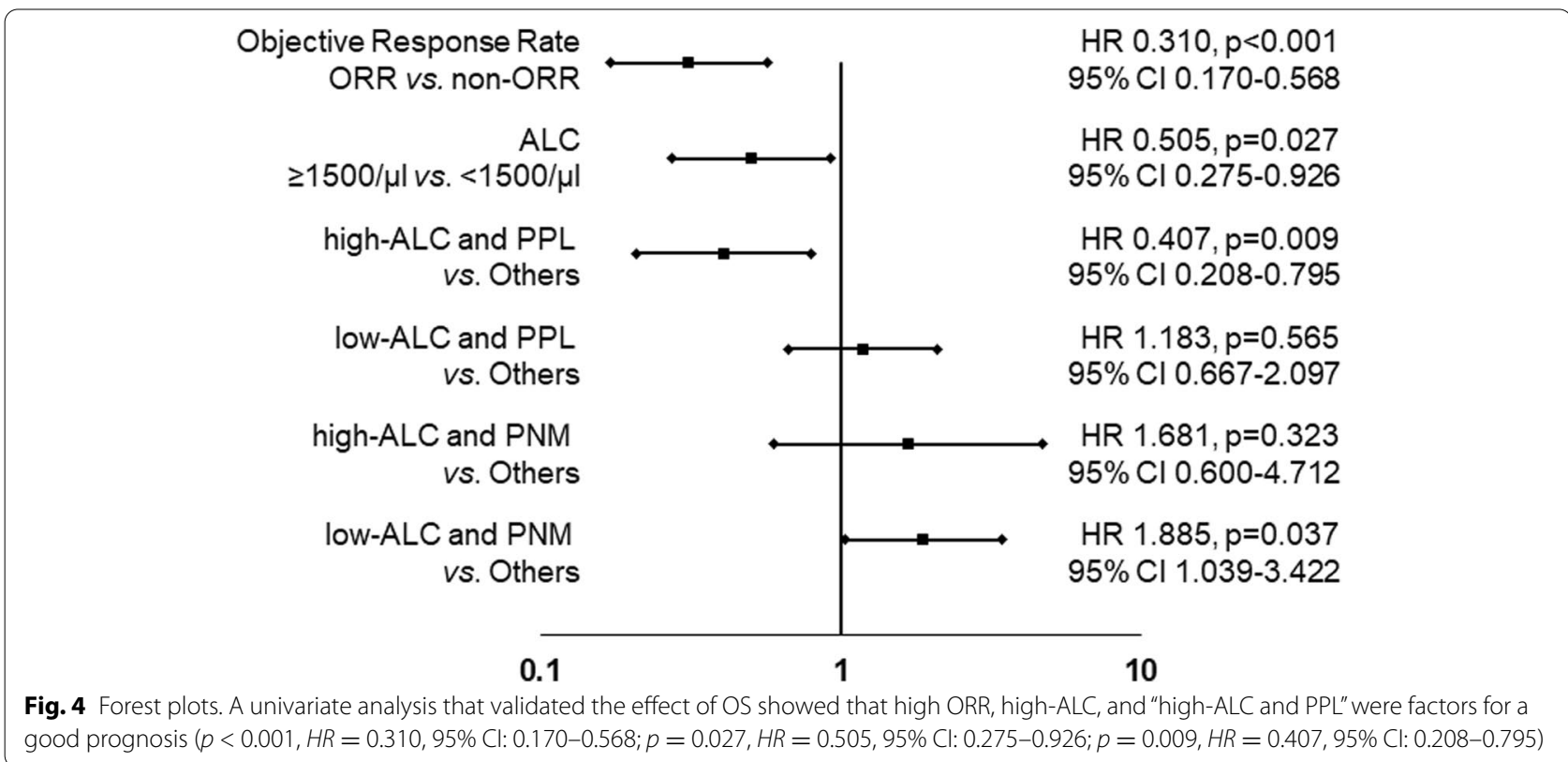

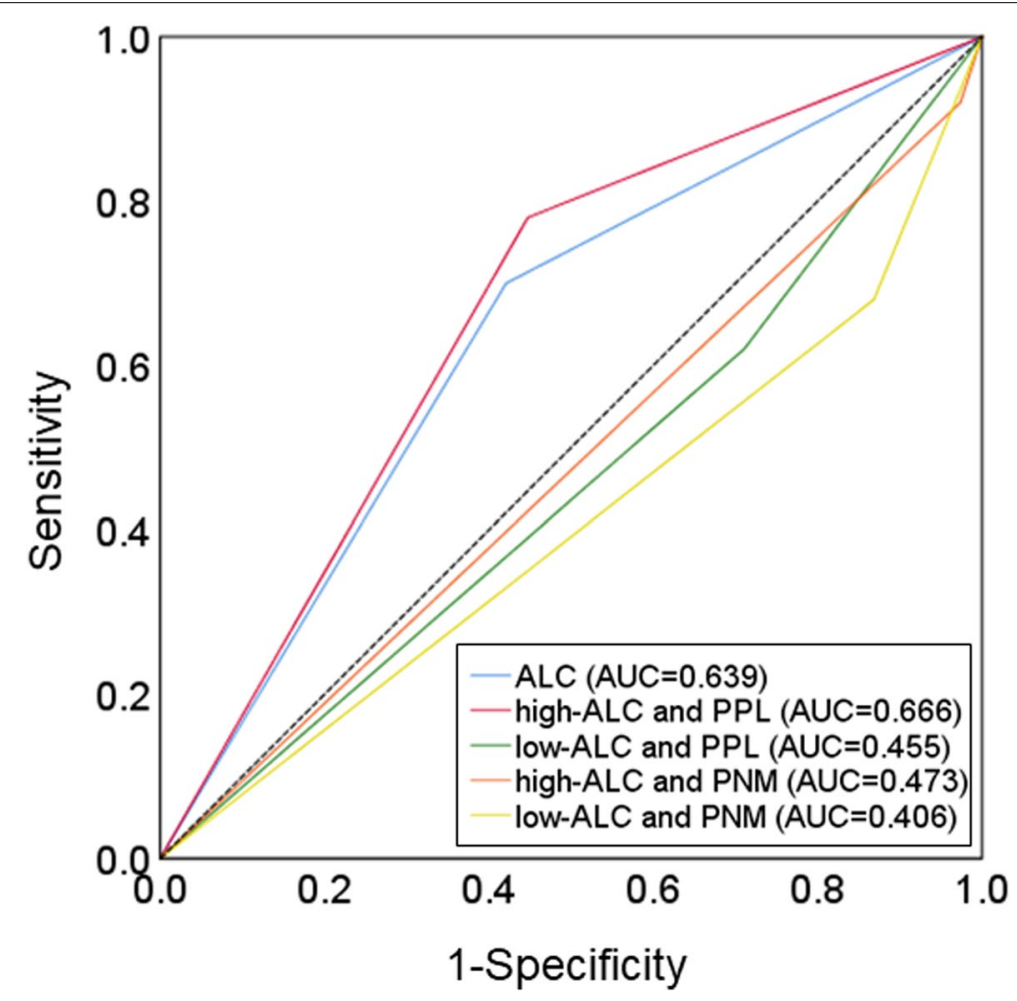

Fig. 5 Receiver operating characteristic (ROC) analysis. ROC analysis showed that the results for "high-ALC and PPL" (area under the curve (AUC): 0.666) were better than those for the ALC (AUC: 0.639), "Iow-ALC and PPL" (AUC: 0.455), "high-ALC and PNM" (AUC: 0.473), and "Iow-ALC and PNM" (AUC: 0.406) 
Table 2 Univariate and multivariate analysis with respect to overall survival in 88 patients with eribulin chemotherapy for locally advanced or metastatic breast cancer

\begin{tabular}{|c|c|c|c|c|c|c|c|}
\hline \multirow{2}{*}{ Parameters } & & \multicolumn{3}{|c|}{ Univariate analysis } & \multicolumn{3}{|c|}{ Multivariate analysis } \\
\hline & & Hazard ratio & $95 \% \mathrm{Cl}$ & $p$ value & Hazard ratio & $95 \% \mathrm{Cl}$ & $p$ value \\
\hline Age at chemotherapy & $\leq 63$ vs. $>63$ & 0.653 & $0.366-1.164$ & 0.148 & & & \\
\hline Degree of progress & Locally advanced vs. visceral metastases & 0.622 & $0.328-1.178$ & 0.144 & & & \\
\hline HR (ER and/or PgR) & Positive vs. negative & 0.630 & $0.359-1.107$ & 0.108 & & & \\
\hline HER2 & Positive vs. negative & 0.366 & $0.089-1.506$ & 0.164 & & & \\
\hline Ki67 & $\leq 14 \%$ vs. $>14 \%$ & 1.401 & $0.803-2.446$ & 0.235 & & & \\
\hline Nuclear grade & 1,2 vs. 3 & 1.501 & $0.842-2.673$ & 0.168 & & & \\
\hline Objective response rate & ORR vs. non-ORR & 0.310 & $0.170-0.568$ & $<0.001$ & 0.321 & $0.171-0.602$ & $<0.001$ \\
\hline ALCs & $\geq 1500 / \mu \mathrm{l} v s .<1500 / \mu \mathrm{l}$ & 0.505 & $0.275-0.926$ & 0.027 & 0.424 & $0.138-1.300$ & 0.133 \\
\hline Progression & $\begin{array}{l}\text { Progression due to preexisting lesions and } \\
\text { high-ALCs vs. Others }\end{array}$ & 0.407 & $0.208-0.795$ & 0.009 & 0.290 & $0.091-0.923$ & 0.036 \\
\hline Progression & $\begin{array}{l}\text { Progression due to preexisting lesions and low- } \\
\text { ALCs vs. others }\end{array}$ & 1.183 & $0.667-2.097$ & 0.565 & & & \\
\hline Progression & $\begin{array}{l}\text { Progression due to new metastasis and high- } \\
\text { ALCs vs. others }\end{array}$ & 1.681 & $0.600-4.712$ & 0.323 & & & \\
\hline Progression & $\begin{array}{l}\text { Progression due to new metastasis and low- } \\
\text { ALCs vs. others }\end{array}$ & 1.885 & $1.039-3.422$ & 0.037 & 1.654 & $0.846-3.234$ & 0.142 \\
\hline
\end{tabular}

$H R$ hormone receptor, $E R$ estrogen receptor, $P g R$ progesterone receptor, $H E R 2$ human epidermal growth factor receptor, $O R R$ objective response rate, $A L C$ absolute lymphocyte count, $\mathrm{Cl}$ confidence interval

there was no significant difference in PFS, and the reason for this is being investigated [16]. The modulating effect of eribulin on the tumor microenvironment through tumor vascular remodeling and epithelial-mesenchymal transition (EMT) suppression is a possible mechanism for OS prolongation [29-31]. In our previous study, which analyzed tissue specimens collected after eribulin treatment, tumor microenvironment (TME) improvement, such as reduced tumor hypoxia and EMT suppression, was observed in the responders [32]. Furthermore, a study using the same tissue specimens showed decreased expression of programmed cell death protein (PD)-1, programmed death ligand-1 (PD-L1), and forkhead box P3 (FOXP3) as well as increased expression of CD8 [33]. The eribulin-resistant MDA-MB-231 breast cancer cell line also showed lower CD274 (PD-L1) expression than the parental cell line [34]. These results indicated an improvement in tumor immunity with eribulin chemotherapy.

ALC and NLR, which are indicators of systemic tumor immune response, have been reported to be prognostic and predictive of therapeutic response in patients treated with eribulin. This was supported by the results of the EMBRACE study [17-19, 24]. We have also shown that local and systemic tumor immune responses are linked via transforming growth factor- $\beta$ (TGF- $\beta$ ) [20].

The RECIST diagnostic criteria for PD were divided into PPL and PNM. Those with PNM had a worse prognosis than those with PPL in Studies 305 and 301 [3]. In the present study, the progression form of PNM had a worse prognosis than PPL in patients treated with eribulin. PNM is associated with peripheral tissue invasion and metastasis to other organs, explaining the poor prognostic course. On the other hand, PPL is associated with peripheral tissue invasion only, without metastasis $[2-4,35]$. In other words, differences in progression patterns are related to dynamic changes in the TME. The rates of PNM in this study were $13.5 \%(5 / 37)$ in highALC cases $(\mathrm{ALC} \geq 1500 / \mu \mathrm{l})$ and less than $23.5 \%(12 / 51)$ in low-ALC cases (ALC $<1500 / \mu \mathrm{l})$. That is, patients with higher ALC had a lesser form of PNM progression. Although ALC is a useful biomarker for eribulin chemotherapy, its mechanism has not been validated until now. The results of our study suggest that a good systemic immune status contributes to benefit in terms of OS. A good local tumor immune microenvironment reduces the progression of PNM. Our previous study showed that systemic and local tumor immune responses were linked to eribulin chemotherapy [20], and the present study showed that the form of progression was a factor. In other words, high-ALC cases (ALC $\geq 1500 / \mu \mathrm{l}$ ) had more PPL and better prognosis than the progression form of PNM due to their better immune status. Furthermore, the use of the combination of "form of PD" and "host's immune systemic marker, ALC" was more sensitive than using ALC alone. In particular, "high ALC and PPL" were independent favorable prognostic factors for overall survival. Good systemic immune status and progressive forms of PPL suggested a good prognosis. However, indicators such as "low ALC and PPL", "high ALC and PNM", and "low ALC and PNM" were not useful as biomarkers. 
This study had limitations since it involved a retrospective cohort analysis with a small sample size. However, this is the first report to capture the mechanism behind the role of ALC as a useful biomarker in eribulin chemotherapy in a progressive form of cancer. We developed a new biomarker, "high-ALC and PPL", which was found to be more sensitive than ALC alone. In the future, these biomarkers should also be considered in clinical practice to determine the best treatment options.

\section{Conclusions}

The progression form of PNM had a worse prognosis than PPL in patients treated with eribulin. In breast cancer patients with eribulin chemotherapy, good systemic immune status, such as ALC $\geq 1500 / \mu l$, was associated with less progression, particularly metastasis, and better prognosis. Furthermore, the biomarker "high-ALC (ALC $\geq 1500 / \mu \mathrm{l})$ and PPL" was particularly useful as a prognostic marker following eribulin chemotherapy.

\section{Abbreviations}

ALC: Absolute lymphocyte count; AUC: Area under the curve; Cl: Confidence interval; CR: Complete response; EMT: Epithelial-mesenchymal transition; ER: Estrogen receptor; H.E.: Hematoxylin and eosin; FOXP3: Forkhead box P3; HER2: Human epidermal growth factor receptor 2; HR: Hazard ratio; LMR: Lymphocyte-monocyte ratio; MBC: Locally advanced or metastatic breast cancer; NLR: Neutrophil-lymphocyte ratio; ORR: Objective response rate; OS: Overall survival; PD: Progression disease; RECIST: Response Evaluation Criteria for Solid Tumors; ROC: Receiver operating characteristic; PD-L1: Programmed death ligand-1; PFS: Progression-free survival; PgR: Progesterone receptor; PLR: Platelet-lymphocyte ratio; PNM: Progression by new metastases; PPL: Progression by preexisting disease; PR: Partial response; TME: Tumor microenvironment; TGF- $\beta$ : Transforming growth factor- $\beta$.
\end{abstract}

\section{Acknowledgments}

We thank Yayoi Matsukiyo and Tomomi Okawa (Department of Breast and Endocrine Surgery, Osaka City University Graduate School of Medicine) for the helpful advice regarding data management.

\section{Authors' contributions \\ All authors were involved in the preparation of this manuscript. TM collected the data and wrote the manuscript. SK, YA, WG, KT, and SI performed the oper- ation and designed the study. TM and SK summarized the data and revised the manuscript. MS, HT, KH, and MO provided a substantial contribution to the study design, performed the operation, and revised the manuscript. The authors read and approved the final manuscript.}

\section{Funding}

This study was supported in part by Grants-in-Aid for Scientific Research (KAKENHI, Nos. 19K18067, 17K10559, and 20K08938) from the Ministry of Education, Science, Sports, Culture and Technology of Japan.

\section{Availability of data and materials}

The datasets used and/or analyzed during the current study are available from the corresponding author on reasonable request.

\section{Declarations}

\section{Ethics approval and consent to participate}

A written informed consent to participate in the study was obtained from each subject in accordance with the Declaration of Helsinki principles. Each patient or the patient's family was fully informed of the investigational nature of this study and provided their written, informed consent. The study protocol was approved by the Ethics Committee of Osaka City University (approve number \#926).

\section{Consent for publication}

Not applicable.

\section{Competing interests}

The authors declare that they have no competing interests.

\section{Author details}

${ }^{1}$ Department of Breast and Endocrine Surgery, Osaka City University Graduate School of Medicine, 1-4-3 Asahi-machi, Abeno-ku, Osaka 545-8585, Japan.

${ }^{2}$ Department of Gastrointestinal Surgery, Osaka City University Graduate

School of Medicine, 1-4-3 Asahi-machi, Abeno-ku, Osaka 545-8585, Japan.

Received: 29 April 2021 Accepted: 2 November 2021

Published online: 15 November 2021

\section{References}

1. Eisenhauer EA, Therasse P, Bogaerts J, Schwartz LH, Sargent D, Ford R, et al. New response evaluation criteria in solid tumours: revised RECIST guideline (version 1.1). Eur J Cancer. 2009;45:228-47.

2. Litiere S, de Vries EGE, Seymour L, Sargent D, Shankar L, Bogaerts J, et al. The components of progression as explanatory variables for overall survival in the Response Evaluation Criteria in Solid Tumours 1.1 database. Eur J Cancer. 2014:50:1847-53.

3. Twelves C, Cortes J, Kaufman PA, Yelle L, Awada A, Binder TA, Olivo M, Song J, O'Shaughnessy JA, Jove M, Perez EA. "New" metastases are associated with a poorer prognosis than growth of preexisting metastases in patients with metastatic breast cancer treated with chemotherapy. Breast Cancer Res. 2015;17:150.

4. Kashiwagi S, Tsujio G, Asano Y, Goto W, Takada K, Takahashi K, et al. Study on the progression types of cancer in patients with breast cancer undergoing eribulin chemotherapy and tumor microenvironment. J Transl Med. 2018;16:54

5. Zhao G, Liu N, Wang S, Guo J, Song X, Qi Y, et al. Prognostic significance of the neutrophil-to-lymphocyte and platelet-to-lymphocyte ratio in patients with metastatic gastric cancer. Medicine. 2020;99:e19405.

6. Tang $X$, Du P, Yang Y. The clinical use of neutrophil-to-lymphocyte ratio in bladder cancer patients: a systematic review and meta-analysis. Int J Clin Oncol. 2017;22:817-25.

7. Kumarasamy C, Sabarimurugan S, Madurantakam RM, Lakhotiya K, Samiappan S, Baxi S, et al. Prognostic significance of blood inflammatory biomarkers NLR, PLR, and LMR in cancer-a protocol for systematic review and meta-analysis. Medicine. 2019;98:e14834.

8. Wei B, Yao M, Xing C, Wang W, Yao J, Hong Y, et al. The neutrophil lymphocyte ratio is associated with breast cancer prognosis: an updated systematic review and meta-analysis. Onco Targets Ther. 2016;9:5567-75.

9. Asano Y, Kashiwagi S, Onoda N, Noda S, Kawajiri H, Takashima T, et al. Predictive value of neutrophil/lymphocyte ratio for efficacy of preoperative chemotherapy in triple-negative breast cancer. Ann Surg Oncol. 2016;23:1104-10.

10. Asano Y, Kashiwagi S, Onoda N, Noda S, Kawajiri H, Takashima T, et al. Platelet-lymphocyte ratio as a useful predictor of the therapeutic effect of neoadjuvant chemotherapy in breast cancer. PLoS One. 2016;11:e0153459.

11. Goto W, Kashiwagi S, Asano Y, Takada K, Takahashi K, Hatano T, et al. Predictive value of lymphocyte-to-monocyte ratio in the preoperative setting for progression of patients with breast cancer. BMC Cancer. 2018;18:1137.

12. Tanaka H, Muguruma K, Toyokawa T, Kubo N, Ohira M, Hirakawa K. Differential impact of the neutrophil-lymphocyte ratio on the survival of patients with stage IV gastric cancer. Dig Surg. 2014;31:327-33.

13. Tanaka H, Tamura T, Toyokawa T, Muguruma K, Miki Y, Kubo N, et al. Clinical relevance of postoperative neutrophil-lymphocyte ratio (NLR) to recurrence after adjuvant chemotherapy of S-1 for gastric cancer. Anticancer Res. 2018:38:3745-51. 
14. Shibutani M, Maeda K, Nagahara H, Fukuoka T, Matsutani S, Kimura K, et al. The prognostic significance of the advanced lung cancer inflammation index in patients with unresectable metastatic colorectal cancer: a retrospective study. BMC Cancer. 2019;19:241.

15. Shibutani M, Maeda K, Nagahara H, Ohtani H, Iseki Y, Ikeya T, et al. The prognostic significance of a postoperative systemic inflammatory response in patients with colorectal cancer. World J Surg Oncol. 2015;13:194.

16. Cortes J, O'Shaughnessy J, Loesch D, Blum JL, Vahdat LT, Petrakova K, et al. Eribulin monotherapy versus treatment of physician's choice in patients with metastatic breast cancer (EMBRACE): a phase 3 open-label randomised study. Lancet. 2011;377:914-23.

17. Miyoshi Y, Yoshimura Y, Saito K, Muramoto K, Sugawara M, Alexis K, et al. High absolute lymphocyte counts are associated with longer overall survival in patients with metastatic breast cancer treated with eribulin-but not with treatment of physician's choice-in the EMBRACE study. Breast Cancer. 2020;27:706-15.

18. Watanabe J, Saito M, Horimoto Y, Nakamoto S. A maintained absolute lymphocyte count predicts the overall survival benefit from eribulin therapy, including eribulin re-administration, in HER2-negative advanced breast cancer patients: a single-institutional experience. Breast Cancer Res Treat. 2020;181:211-20.

19. Miyagawa Y, Araki K, Bun A, Ozawa H, Fujimoto Y, Higuchi T, et al. Significant association between low baseline neutrophil-to-lymphocyte ratio and improved progression-free survival of patients with locally advanced or metastatic breast cancer treated with eribulin but not with nab-paclitaxel. Clin Breast Cancer. 2018;18:400-9.

20. Kashiwagi S, Asano Y, Goto W, Takada K, Morisaki T, Kouhashi R, et al. Validation of systemic and local tumour immune response to eribulin chemotherapy in the treatment of breast cancer. Anticancer Res. 2020:40:3345-54.

21. Kashiwagi S, Asano Y, Goto W, Takada K, Takahashi K, Noda S, et al. Use of tumor-infiltrating lymphocytes (TILs) to predict the treatment response to eribulin chemotherapy in breast cancer. PLoS One. 2017;12:e0170634.

22. Kashiwagi S, Fukushima W, Asano Y, Goto W, Takada K, Noda S, et al. Identification of predictive markers of the therapeutic effect of eribulin chemotherapy for locally advanced or metastatic breast cancer. BMC Cancer. 2017:17:604.

23. Schoffski P, Chawla S, Maki RG, Italiano A, Gelderblom H, Choy E, et al. Eribulin versus dacarbazine in previously treated patients with advanced liposarcoma or leiomyosarcoma: a randomised, open-label, multicentre, phase 3 trial. Lancet. 2016;387:1629-37.

24. Ueno A, Maeda R, Kin T, Ito M, Kawasaki K, Ohtani S. Utility of the absolute lymphocyte count and neutrophil/lymphocyte ratio for predicting survival in patients with metastatic breast cancer on eribulin: a real-world observational study. Chemotherapy. 2019;64:259-69.
25. Rossari JR, Metzger-Filho O, Paesmans M, Saini KS, Gennari A, de Azambuja E, et al. Bevacizumab and breast cancer: a meta-analysis of first-line phase III studies and a critical reappraisal of available evidence. J Oncol. 2012;2012:417673.

26. Miller K, Wang M, Gralow J, Dickler M, Cobleigh M, Perez EA, et al. Paclitaxel plus bevacizumab versus paclitaxel alone for metastatic breast cancer. N Engl J Med. 2007;357:2666-76.

27. Miles DW, Chan A, Dirix LY, Cortes J, Pivot X, Tomczak P, et al. Phase III study of bevacizumab plus docetaxel compared with placebo plus docetaxel for the first-line treatment of human epidermal growth factor receptor 2-negative metastatic breast cancer. J Clin Oncol. 2010;28:3239-47.

28. Robert NJ, Dieras V, Glaspy J, Brufsky AM, Bondarenko I, Lipatov ON, et al. RIBBON-1: randomized, double-blind, placebo-controlled, phase III trial of chemotherapy with or without bevacizumab for first-line treatment of human epidermal growth factor receptor 2-negative, locally recurrent or metastatic breast cancer. J Clin Oncol. 2011;29:1252-60.

29. Fukumura D, Kloepper J, Amoozgar Z, Duda DG, Jain RK. Enhancing cancer immunotherapy using antiangiogenics: opportunities and challenges. Nat Rev Clin Oncol. 2018;15:325-40.

30. Ueda S, Saeki T, Takeuchi H, Shigekawa T, Yamane T, Kuji I, et al. In vivo imaging of eribulin-induced reoxygenation in advanced breast cancer patients: a comparison to bevacizumab. Br J Cancer. 2016;114:1212-8.

31. Ito K, Hamamichi S, Abe T, Akagi T, Shirota H, Kawano S, et al. Antitumor effects of eribulin depend on modulation of the tumor microenvironment by vascular remodeling in mouse models. Cancer Sci. 2017;108:2273-80.

32. Kashiwagi S, Asano Y, Goto W, Takada K, Takahashi K, Hatano T, et al. Mesenchymal-epithelial transition and tumor vascular remodeling in eribulin chemotherapy for breast cancer. Anticancer Res. 2018;38:401-10.

33. Goto W, Kashiwagi S, Asano Y, Takada K, Morisaki T, Fujita H, et al. Eribulin promotes antitumor immune responses in patients with locally advanced or metastatic breast cancer. Anticancer Res. 2018;38:2929-38.

34. Goto W, Kashiwagi S, Asano Y, Takada K, Takahashi K, Fujita H, et al. The effects of eribulin on breast cancer microenvironment identified using eribulin-resistant breast cancer cell lines. Anticancer Res. 2019;39:4031-41.

35. Fujii T, Tokuda S, Nakazawa Y, Kurozumi S, Obayashi S, Yajima R, et al. Eribulin suppresses new metastases in patients with metastatic breast cancer. In Vivo. 2020;34:917-21.

\section{Publisher's Note}

Springer Nature remains neutral with regard to jurisdictional claims in published maps and institutional affiliations.

Ready to submit your research? Choose BMC and benefit from

- fast, convenient online submission

- thorough peer review by experienced researchers in your field

- rapid publication on acceptance

- support for research data, including large and complex data types

- gold Open Access which fosters wider collaboration and increased citations

- maximum visibility for your research: over $100 \mathrm{M}$ website views per year

At BMC, research is always in progress.

Learn more biomedcentral.com/submissions 